\title{
Encaminhamento de estudantes com deficiência aos serviços de Educação Especial em Manaus: quais os critérios?
}

\author{
Márcia Duarte Galvani ${ }^{1}$ \\ Samuel Vinente ${ }^{2}$
}

\begin{abstract}
RESUMO
O presente estudo objetivou analisar os critérios no encaminhamento de estudantes com deficiência aos serviços de Educação Especial em Manaus. Trata-se de um estudo descritivo, com utilização das técnicas de entrevista e pesquisa documental. Utilizou-se como instrumento roteiros semistruturados de entrevista a quatro professores (P1, P2, P3 e P4) e um representante da Gerência de Educação Especial (P5). A pesquisa documental foi realizada na legislação municipal publicada entre $1991 \mathrm{e}$ 2017. Os resultados apontam que o encaminhamento desses estudantes aos serviços de Educação Especial é realizado mediante avaliação multidisciplinar de profissionais do Complexo Municipal de Educação Especial, focalizando-se mais em uma abordagem médico-clínica que na perspectiva pedagógica e dos direitos humanos. Os critérios de identificação, avaliação e encaminhamento dos estudantes com deficiência precisam ser delineados, considerando as especificidades dos alunos e a questão do direito educacional na oferta desses serviços.
\end{abstract}

PALAVRAS-CHAVE: Educação Especial. Política Educacional. Serviços Especializados.

\footnotetext{
1 Doutora em Educação Escolar pela Universidade Estadual Paulista Júlio de Mesquita Filho (UNESP Araraquara)Docente do Programa de Pós-Graduação em Educação Especial da Universidade Federal de São Carlos (UFSCar), SP, Brasil. https://orcid.org/0000-0003-1092-746X.marciaduar@yahoo.com.br.

${ }^{2}$ Mestre e Doutorando em Educação Especial pela Universidade Federal de São Carlos (UFSCar), São Carlos, SP, Brasil. https://orcid.org/0000-0002-7205-9680. samueljunior.ns@gmail.com.
} 
Referral of students with disabilities to Special Education services in Manaus: what are the criteria?

\begin{abstract}
This study aimed at the referral session of students with disabilities to the Special Education services in the Manaus. This is a descriptive study, using interview techniques and documentary research. It was used as a scripted interview instrument for four teachers (P1, P2, P3 and P4) and a representative of the Special Education Management (P5). The documentary research was carried out in a municipal education published between 1991 and 2017. The results pointed out that the sending of data to the education services was special throughout 1991 and 2017. The clinic aimed at pedagogical perspective and human rights. The criteria for identification, assessment and referral of students with disabilities need to be delineated, taking into account the specificities of the students and a question of law.
\end{abstract}

KEYWORDS: Special education. Educational politics. Specialized Services.

$$
* * *
$$

\title{
Introdução
}

No Brasil o atual público-alvo da Educação Especial (PAEE) foi definido pelo Decreto $\mathrm{n}^{\circ} 7.611 / 2011$, baseando-se então nos estudantes com deficiência, transtornos globais do desenvolvimento e altas habilidades/superdotação (BRASIL, 2011). A própria Educação Especial apresenta-se na legislação educacional enquanto modalidade de educação escolar, ofertada preferencialmente no ensino regular (BRASIL, 1996, 2013).

Ao assegurar os serviços de Atendimento Educacional Especializado (AEE) aos estudantes PAEE, a legislação definiu essa proposta de atendimento enquanto um "[...] conjunto de atividades, recursos de acessibilidade e pedagógicos organizados institucional e continuamente" (BRASIL, 2011, art. $2^{\circ}$ ). 
O AEE pode ser ofertado de forma complementar aos estudantes com deficiência e transtornos globais do desenvolvimento e no formato suplementar, aos estudantes com altas habilidades/superdotação. Considerando então a Política Nacional de Educação Especial na Perspectiva da Educação Inclusiva - PNEEP-EI (BRASIL, 2008), o AEE assume enquanto objetivo:

[...] o acesso, a participação e a aprendizagem dos estudantes com deficiência, transtornos globais do desenvolvimento e altas habilidades/superdotação nas escolas regulares, orientando os sistemas de ensino para promover respostas às necessidades educacionais [...]" (BRASIL, 2008, p. 10)

Como pode-se observar no trecho transcrito da PNEEP-EI, a proposta do AEE orienta os sistemas de ensino na oferta de um serviço especializado na rede regular de ensino, constituindo-se então no cenário nacional a implementação do ideário de inclusão total. Segundo Mendes (2006) essa proposta estabelece então, um tipo de política sem exceção, fundamentanda na ética da participação, sem a preocupação com os ganhos acadêmicos.

Os estudos sobre a organização desse atendimento têm fomentado uma ampla discussão sobre os diferentes modelos de AEE que foram constituídos nos diferentes municípios brasileiros. A literatura mais recente vem apontando que a oferta desses serviços consideram mais especificamente a implantação das Salas de Recursos Multifuncionais (SRM), conforme nos apontam Mendes, Cia (2012), Pletsch (2012), Milanesi (2012), Nozu (2013) e Vinente (2017).

As SRM são definidas como espaços "[...] dotados de equipamentos, mobiliários e materiais didáticos e pedagógicos para a oferta do atendimento educacional especializado" (BRASIL, 2011, art. 5\%). As salas do Tipo I são destinadas ao atendimento de crianças com os mais variados quadros clínicos. As salas do tipo II, possuem todos os recursos das Salas Tipo I, sendo acrescentados materiais específicos para o atendimento aos estudantes com deficiência visual. 
As mudanças na conceituação da Educação Especial e na oferta dos serviços vinculados a essa modalidade de educação escolar trazem elementos significativos para a discussão de uma política brasileira que se implementa nos municípios de forma multifacetada. Tais políticas trazem implicações profundas para o trabalho pedagógico na Educação Especial (GARCIA, 2006; OLIVEIRA, 2016; VINENTE, 2017).

Do ponto de vista de Harlos, Denari e Orlando (2014), analisar as mudanças conceituais e estruturais na Educação Especial é essencial para a adequada atuação dos profissionais, bem como a possibilidade de adoção de um posicionamento crítico diante das proposições e retóricas difundidas nos documentos nacionais e internacionais.

Uma das principais preocupações dos pesquisadores da área diz respeito não somente a como esses serviços são ofertados, mas desdobra-se também nos aspectos referentes à formação dos professores e organização dos espaços que atendem a esses estudantes. Além disso, alguns trabalhos vêm analisando a questão do encaminhamento dos estudantes PAEE aos serviços de Educação Especial (PRIETO; SOUSA, 2007; SILVA, 2010; PLETSCH, 2012; CORRÊA, 2013; SEMKIV, 2014; PIETROBOM, 2016; OLIVEIRA, 2016).

Buscando então analisar os argumentos de professores de classes comuns para o encaminhamento de alunos para a sala de recursos, Silva (2010) realizou entrevistas com professores e realizou levantamento da legislação municipal, além de analisar os relatórios dos encaminhamentos. Os dados fazem referência à defasagem de aprendizagem, item fortemente descrito nos relatórios analisados. Visualizou-se também itens como as condições precárias de trabalho, de formação continuada insuficiente, da ausência de espaços coletivos, entre outros aspectos.

Corrêa (2013), ao buscar analisar a avaliação, o diagnóstico e o encaminhamento de estudantes PAEE em Londrina, realizou entrevistas com a equipe psicopedagógica e análise dos laudos de encaminhamento, bem como os critérios para avaliação e diagnóstico. Os dados apontaram que a 
ênfase é dada ao indivíduo, em detrimento da questão pedagógica. $\mathrm{O}$ encaminhamento é sempre realizado após avaliações psicológicas e testes psicométricos. Os dados levaram a inferir que, embora tenha havido mudanças na proposta de Educação Especial para a perspectiva da Educação Inclusiva, a mesma permanece como um sistema paralelo de ensino.

O trabalho de Semkiv (2014), ao analisar a dinâmica de avaliação, diagnóstico e encaminhamento de crianças com deficiência em um município no interior do Paraná, realizou entrevistas com profissionais que atuavam nesse processo tais como psicopedagoga, psicóloga, fonoaudióloga e pedagoga. Os resultados apontaram que a avaliação carrega aspectos clínicos que categorizam as deficiências antes do encaminhamento dos estudantes aos serviços de AEE. Além disso, a pesquisa constatou desarticulação entre as profissionais que atuavam durante o processo avaliativo.

Pietrobom (2016), buscando conhecer e analisar o processo de avaliação e de encaminhamento dos alunos PAEE na rede municipal de ensino em Dourado (MS), aplicou questionários a 18 professores que atuavam em SRM. Os dados apontaram que os docentes realizavam modelos diferentes de avaliação, de acordo com sua formação e concepção. O estudo apontou também para a restrição na participação da família, bem como a necessidade de procedimentos mais amplos de avaliação, com menor determinação de laudos médicos.

Além dos estudos já apresentados (SILVA, 2010; CORRÊA, 2013; SEMKIV, 2014; PIETROBOM, 2016), visualizamos os desafios na identificação e encaminhamento desses estudantes também em outras pesquisas (PRIETO; SOUSA, 2007; PLETSCH, 2012; MILANESI, 2012; NOZU, 2013; SEMKIV, 2014; PIETROBOM, 2016; VINENTE, 2017).

Em Manaus, lócus de realização desse estudo, a proposta do AEE vem sendo abordada em alguns estudos (MATOS, 2008; MARQUES, 2010; SANTOS, 2011; BATISTA, 2015), contudo, lacunas como o histórico de 
oferta desses serviços e dados mais consistentes sobre as equipes multiprofissionais que identificam e encaminham esses alunos precisam ser mais identificados e explorados. A análise da legislação municipal pode contribuir na produção do conhecimento científico no sentido de constituir o histórico de oferta dos serviços, bem como os critérios de elegibilidade desses estudantes.

Sendo assim, quais os critérios que são definidos para o encaminhamento de estudantes com deficiência aos serviços de Educação Especial? Como se constituiu historicamente a oferta dos serviços de Educação Especial? Quem realiza a identificação dos alunos a serem atendidos? Quais instrumentos são utilizados?

Com base no exposto, o objetivo desse estudo é analisar os critérios no encaminhamento de estudantes com deficiência aos serviços de Educação Especial da Secretaria Municipal de Educação em Manaus.

\section{Método}

Trata-se de um estudo qualitativo e descritivo (GIL, 2008), no qual utilizou-se a técnica de pesquisa documental (GIL, 2002, 2008) na legislação municipal de ensino. Os estudos descritivos buscam descrever as características de determinadas populações ou fenômenos com a utilização de técnicas padronizadas de dados, como a análise documental e as entrevistas.

O projeto foi submetido ao Comitê de Ética em Pesquisa com Seres Humanos da Universidade Federal de São Carlos (UFSCar), conforme preceitos das Resoluções CNS no 466/2012 e 510/2016, obtendo o Certificado de Apresentação para Apreciação Ética (CAAE) no 9256215.4.0000.5504. Os participantes foram informados quanto aos objetivos, riscos e benefícios do estudo. Após isso, assinaram o Termo de Consentimento Livre e Esclarecido (TCLE), concordando em participar da pesquisa. 
Os dados do estudo foram coletados nas dependências das escolas municipais, localizadas no perímetro urbano da capital amazonense. Com uma população estimada atualmente em 2.130.264 habitantes, Manaus é atualmente a sétima capital mais populosa do país (IBGE, 2018).

Os participantes do estudo foram quatro (4) professores efetivos do gênero feminino ( $\mathrm{P} 1, \mathrm{P} 2$, P3 e P4) selecionados por amostragem por conveniência, de modo que representassem as diferentes zonas geográficas da cidade; e, uma (1) representante da Gerência de Educação Especial do município (P5), totalizando cinco (5) sujeitos.

Foram aplicados Roteiros Semiestruturados de Entrevista para os professores do AEE e para a Representante da Gerência de Educação Especial do município. Os roteiros foram confeccionado com perguntas principais, complementadas por outras questões inerentes às circunstâncias momentâneas da entrevista. Foram constituídos por aproximadamente quarenta questões, abertas e fechadas.

Inicialmente foi realizada a pesquisa documental na legislação do município, publicada no Diário Oficial (MANAUS, 1991, 1997, 1998, 2003, 2007, 2011, 2016, 2017), compreendendo o período de 1991 a 2017. Como ocorrem em outras abordagens de pesquisa qualitativa, os documentos e análise de documentos podem ser utilizados como estratégia complementar para métodos como a entrevista (FLICK, 2009).

Posteriormente, foi realizada a entrevista com a representante da Gerência da Educação Especial (P5), em espaço determinado e horário previamente agendado. Após isso, realizou-se a entrevista com as professoras (P1, P2, P3 e P4), no próprio local de trabalho das participantes.

As entrevistas foram transcritas levando em consideração as discussões propostas por Manzini (2004), identificando os discursos que respondessem aos objetivos da pesquisa. Os dados foram analisados por meio de elaboração de categorias, que foram emergindo a partir da audição das entrevistas e análise dos dados. Durante o processo de transcrição do material foram retirados alguns vícios de linguagem e optamos por suprimir 
trechos que não respondiam aos objetivos do estudo, para que a análise fosse mais objetiva.

\section{Resultados e Discussões}

Os dados serão apresentados e discutidos a partir dos seguintes itens: (1) Histórico do Encaminhamento de Estudantes com Deficiência aos serviços de Educação Especial em Manaus (1991-2017); (2) Bases Legais para o Encaminhamento de Estudantes com Deficiência aos serviços de Educação Especial; e, (3) Identificação e Matrícula dos estudantes com Deficiência em Manaus.

\section{Histórico do Encaminhamento de Estudantes com Deficiência aos serviços de Educação Especial em Manaus (1991-2017)}

Em Manaus, os primeiros registros de atendimento às pessoas com deficiência mental e auditiva, datam de 1892, na Unidade Educacional Euclides da Cunha (JANNUZZI, 2004; BATISTA, 2015). Após isso, entre as primeiras iniciativas filantrópicas para o atendimento desse público, destacamos a instalação do Instituto Montessoriano no ano de 1943 (NASCIMENTO; OLIVEIRA; MARINHO, 2007; BATISTA, 2015; VINENTE, 2017).

Na Secretaria Municipal de Educação, apenas no ano de 1991 é que vamos observar a institucionalização da Educação Especial enquanto modalidade "[...] voltada para atender as pessoas portadoras de deficiência visual, auditiva, mental, as infra-dotadas e as super-dotadas" por meio da publicação da Lei n 050/1991 (MANAUS, 1991).

Dessa forma, mesmo que a Secretaria tenha realizado um levantamento preliminar para o mapeamento de crianças com deficiência que necessitavam dos serviços de Educação Especial (SANTOS, 1998; 
MATOS, 2008; VINENTE, 2017), apenas a partir de 1991 foram registradas as matrículas desses estudantes.

Segundo dados da Secretaria Municipal de Educação, essas matrículas cresceram no período no período de 1991 a 1996. Em 1991, a rede de ensino possuía 246 estudantes matriculados na Educação Especial. Em 1992 esse número foi de 234 alunos. No ano de 1993 observamos uma queda de mais 50\% no quantitativo de matrículas, apenas 97 estudantes. No período de 1994 a 1996 esse número foi ampliado de forma acentuada (em 1994 - 210 estudantes; em 1995 - 587 estudantes e; em 1996 - 693 estudantes).

Visando acompanhar esses estudantes, observamos na literatura uma iniciativa do Poder Público tal como a criação do Núcleo de Educação Especial (SANTOS, 1998; MATOS, 2008; VINENTE, 2017), o qual tinha como objetivo coordenar, acompanhar e avaliar os programas de Educação Especial. Esse dado também foi relatado pela Gerente de Educação Especial do município, que afirmou participar da instituição do Núcleo, o qual posteriormentetambém seria denominado de Seção de Educação Especial.

A Seção de Educação Especial passa então a ser composta por uma equipe de profissionais, que realizavam acompanhamento técnicopedagógico, de forma sistemática, aos profissionais e técnicos que atuavam na área. Entre as principais atribuições da Seção podemos destacar: (a) encaminhamento ao atendimento especializado de estudantes que apresentavam deficiência sensoriais e mentais; (b) orientação aos professores da Educação Especial; (c) desenvolvimento de programas sistemáticos para a prevenção das deficiência; e, (d) elaboração de relatórios e do Plano de Trabalho anual (MANAUS, s. d).

Embora a Seção de Educação Especial realizasse o encaminhamento dos estudantes aos serviços especializados observamos na documentação que a rede de ensino não possuía um Centro de Triagem (MANAUS, s.d.). Assim sendo, os estudantes eram identificados mediante convênio firmado 
entre a Prefeitura de Manaus e o Governo do Estado por intermédio do Centro de Triagem e Avaliação Diagnóstica (CETRIDE).

Apenas em 1997, com a reestruturação da Seção de Educação Especial, é que foram incorporados à equipe seis profissionais que realizavam assessoria pedagógica (SANTOS, 1998). A partir disso, houve a criação do SADEM, o Sistema de Avaliação Diagnóstica da Educação Especial do Município (SANTOS, 1998; MATOS, 2008; VINENTE, 2017). O objetivo do SADEM seria então avaliar e diagnosticar os estudantes para o atendimento especializado ofertado na rede de ensino.

Considerando então a documentação (MANAUS, s.d) e a literatura (SANTOS, 1998; MATOS, 2008; VINENTE, 2017) foi possível verificar que a equipe do SADEM era constituída por um assistente social, um pedagogo, um psicopedagogo, dois psicólogos, dois fonoaudiólogos e dois professores. Dessa forma, questionamos sobre a possibilidade de identificação e avaliação de qualquer estudante com deficiência, tendo em vista que a equipe necessitaria de mais profissionais da área de saúde para um diagnóstico mais preciso.

Em documento entregue às escolas (MANAUS, 1997) verificamos como se dava parte do processo de identificação, avaliação e encaminhamento dos estudantes aos serviços de Educação Especial. Em síntese: (a) se o aluno apresentasse algum indício de dificuldades de aprendizagem, o professor, técnico ou gestor deveriam buscar informações no Departamento de Ensino; (b) era agendada posteriormente uma visita à escola para a checagem da situação do aluno; (c) se algo fosse detectado preenchia-se um formulário e o estudante era encaminhado ao SADEM; e, (d) no SADEM o estudante era submetido à avaliações diagnósticas por meio de testes psicopedagógicos e anamnese.

Nesse cenário, não obtivemos na literatura em Educação Especial do município informações mais precisas sobre como eram realizadas as avaliações. Mais estudos se mostram necessários para identificar quantas sessões eram realizadas, como se dava o registro das avaliações, como a 
escola e a família eram notificadas, e outras informações que podem nos auxiliar na análise desse processo que permeia a história da Educação Especial no município.

Não foram identificados documentos que abordam sobre a extinção do SADEM. Santos (1998), Matos (2008), Marques (2010) apontam que posteriormente a esse serviço se deu a criação do Centro Municipal de Educação Especial André Vidal de Araújo (CMEE). Na legislação (MANAUS, 1997, 1998) pode-se verificar por meio de cruzamento de dados como o endereço, que o SADEM transformou-se na Escola Municipal José Salomão Schartzman, escola essa criada por intermédio da Lei ${ }^{\circ}$ 452/1998 (MANAUS, 1998).

Segundo Marques (2010), a Escola José Salomão Schartzman seria a primeira e única escola especial criada em Manaus, para o atendimento de estudantes com deficiência mental. A legislação aponta que seu funciomento se daria até o ano de 2007, quando a publicação da Lei $n^{\circ}$ 1.102/2007 extiguiria essa escola e a Escola Municipal Emerson Prestes. A mesma lei criou o Complexo Municipal de Educação Especial André Vidal de Araújo (MANAUS, 2007), o qual tornaremos a descrever suas ações no próximo item.

\section{Bases Legais para o Encaminhamento de Estudantes com Deficiência aos serviços de Educação Especial em Manaus}

No âmbito da Secretaria Municipal de Educação, uma das primeiras diretrizes sobre a Educação Especial após criação do Conselho Municipal de Educação foi publicada apenas em 2003, por meio da Resolução $\mathrm{n}^{\circ}$ 005/CME/2003 (MANAUS, 2003).

De acordo com essa resolução, a Educação Especial foi definida como uma modalidade e proposta predagógica que assegurasse recursos e serviços educacionais para apoiar, complementar e em alguns casos substituir os serviços educacionais comuns (MANAUS, 2003). Considerando a legislação 
nacional (BRASIL, 1996, 2001), observamos que a resolução insere em seu texto a possiblidade de manter a oferta da Educação Especial enquanto serviço paralelo ao ensino regular.

O artigo $6^{\circ}$ da Resolução $n^{\circ}$ 005/CME/2003 delineou que o processo de identificação e encaminhamento dos estudantes seria realizado com base nos seguintes critérios: (a) observação do aluno durante ao menos um semestre escolar, proporcionando atendimento às necessidades; (b) esgotados os recursos e persistindo as dificuldades, o professor, técnico ou gestor da escola deveria procurar o CMEE e solicitar visita dos pedagogos; (c) durante a visita, detectadas as dificuldades ou evidências, o professor seria orientado a preencher a ficha de encaminhamento para que o aluno fosse avaliado por profissionais do CMEE; (d) submetido a uma avaliação psicopedagógica por equipe multidisciplinar, o estudante teria um parecer técnico e seriam realizados encaminhamentos aos serviços especializados (MANAUS, 2003).

Observamos na literatura procedimentos semelhantes aos adotados na Secretaria Municipal de Educação em Manaus por sistemas de ensino em outras regiões do país (PRIETO; SOUSA, 2007; SILVA, 2010; PLETSCH, 2012; CORRÊA, 2013; SEMKIV, 2014; PIETROBOM, 2016; OLIVEIRA, 2016). Tais trabalhos questionam os critérios de avaliação e o estigma provenientes dos laudos médicos e pareceres técnicos.

No município de Manaus, após avaliação psicopedagógica realizada por uma equipe multiprofissional, os estudantes poderiam ser encaminhados às classes especiais, às salas de recursos, à escola especial ou poderiam ter disponibilizados pela Secretaria professor itinerante, para orientação e supervisão de professores do ensino regular (MANAUS, 2003).

De acordo com a legislação (MANAUS, 2003) foi possível observar que houve um crescimento da equipe multiprofissional proposta na Resolução $\mathrm{n}^{\circ}$ 005/CME/2003, se comparada ainda à equipe do SADEM (MANAUS, 1997). A resolução $n^{\circ}$ 005/CME/2003 já previa uma equipe constituída por pedagogos, psicopedagogos, fonoaudiólogos, assistentes sociais, terapeutas ocupacionais, fisioterapeutas, neurologistas, odontólogos, oftalmologistas, 
clínicos gerais, otorrinolaringologistas, pediatras e dermatologistas (MANAUS, 2003).

Com a publicação da Resolução n 010/CME/2011 observamos algumas modificações nas bases legais de Educação Especial do município. A primeira diz respeito à definição de Educação Especial, que ancorada na PNEEP-EI (BRASIL, 2008) já não apresentava mais o termo substituição. Além disso, a Resolução passou a incorporar artigos que definiam o AEE e o público-alvo da Educação Especial. Quanto aos locais de oferta do AEE, o documento normatizou apenas as Salas de Recursos (SR) e Salas de Recursos Multifuncionais (SRM), utilizando-se também como suporte o Complexo Municipal de Educação Especial (CMEE).

Os critérios para avaliação e encaminhamentos dos estudantes foram alterados na Resolução n 010/CME/2011, enquanto a anterior considerava que a observação do aluno deveria ocorrer em um semestre, essa já normatizava apenas um bimestre escolar. Além disso, ainda previa-se a visita de um representante de Complexo à escola, porém, somente após a elaboração de um relatório pelo professor com suporte do pedagogo ou gestor escolar.

Após esses procedimentos, o estudante era submetido a uma avaliação psicopedagógica realizada por uma equipe multiprofissional. Verificou-se com base na análise dos documentos (MANAUS, 2003, 2011), uma revisão quanto à composição da equipe, a qual passou a ser constituída apenas por pedagogos, psicopedagogos, fonoaudiólogos, psicólogos, assistentes sociais, terapeutas ocupacionais, fisioterapeutas e odontólogos (MANAUS, 2011).

Criado em 2007, por intermédio da Lei $\mathrm{n}^{\circ}$ 1.102/2007, o Complexo Municipal de Educação Especial ainda é o setor responsável na SEMED pela pela avaliação dos estudantes matriculados na rede de ensino. De acordo com relatos da Gerente de Educação Especial do município, é realizado um estudo de caso, antes da definição do serviço de AEE a ser ofertado ao estudante. 
A Resolução $\mathrm{n}^{\circ}$ 011/CME/2016, dispositivo mais recente que orienta sobre os serviços de Educação Especial no município, já não menciona o Complexo Municipal de Educação Especial. Ao tratar sobre a avaliação da deficiência, o documento aponta que, essa deverá ser biopsicossocial e realizada por equipe multiprofissional e interdisciplinar.

A avaliação deverá considerar então: (a) os impedimentos nas funções e estruturas; (b) os fatores socioambientais, psicológicos e sociais; (c) a limitação no desempenho de atividades, e; (d) a restrição de participação. A Resolução também determina que as instituições de ensino privado poderão criar centros especializados para identificação e atendimento de seus estudantes (MANAUS, 2016).

Tendo em vista que as bases legais do município já foram apresentadas, sendo contextualizadas as modificações na legislação, discutiremos no próximo item sobre a matrícula e o encaminhamento dos estudantes à rede pública de ensino, com base nos relatos dos participantes do estudo.

\section{Identificação e Matrícula dos estudantes com Deficiência em Manaus}

De acordo com os relatos dos participantes (P1, P2, P3, P4 e P5), uma assessora representante da Gerência de Educação Especial se desloca à escola após consulta da equipe da gestão escolar à Gerência. Com esse deslocamento a assessora objetiva auxiliar a equipe pedagógica da escola no processo de identificação de potenciais estudantes público-alvo da Educação Especial.

Tais alunos podem ser encaminhados às Classes Especiais, Salas de Recursos ou Salas de Recursos Multifuncionais. Visualizamos semelhanças na forma como esse processo de identificação e avaliação é conduzido em outros estudos (PRIETO; SOUSA, 2007; SILVA, 2010; PLETSCH, 2012; CORRÊA, 2013; SEMKIV, 2014; PIETROBOM, 2016; OLIVEIRA, 2016). 
Embora o serviço de classes especiais seja mencionado nos relatos dos participantes, não há na atual Resolução item algum que regulamente a Educação Especial no município (MANAUS, 2016), bem como nenhuma menção a esse serviço. No entanto, observamos ainda a existência de 28 classes especiais, das quais a maioria encontra-se localizada nas zonas norte e leste do município (VINENTE, 2017).

Outra forma de identificação dos possíveis estudantes que frequentam os serviços de Educação Especial baseia-se na observação realizada pelo professor, de modo que seja possível reconhecer a necessidade de um suporte maior para os estudantes matriculados na rede. Segundo P1, "[...] a partir da avaliação do CMEE, eles são encaminhados para a SR. Muitas vezes, até pelo próprio laudo, o médico já encaminha para frequentar uma SRM ou uma SR (P1, 2016)".

Nem sempre esse processo de identificação ocorre dessa forma. De acordo com P2, quando a escola recebe um "aluno especial", "[...] geralmente a família vem e conversa [...] relata que é uma criança especial, que tem essa ou aquela deficiência". Após conversa entre a família e o professor, a escola verifica se há algum laudo médico para o registro do quadro clínico, de modo que a equipe escolar possa acompanhar o aluno e realizar a matrícula.

Quanto à avaliação realizada pelo CMEE, P3 aponta que trata-se de uma avaliação multidisciplinar realizada por uma "[...] equipe com fonoaudiólogo, educador físico, psicólogo e pedagogo. Daí, [o estudante] é avaliado e encaminhado para um neuropediatra" (P3, 2016). Após, essa avaliação, a participante sinalizou que o estudante é encaminhado para uma escola que possua SEM, de modo que este possa usufruir de um serviço especializado.

Considerando então o processo de avaliação desse alunado e a matrícula no estabelecimento de ensino, a Resolução no 011/CME/2016 dispõe sobre a chamada pública para matrícula antecipada. O objetivo da chamada é que os estudantes PAEE tenham as matrículas realizadas de 
forma antecipada, visando assegurar as vagas e evitar possíveis transtornos. Nessa perspectiva trata-se de um atendimento prioritário.

Fica estabelecido na Resolução que essa antecipação do período de matrícula dos estudantes PAEE não os impedem de terem a matrícula efetuada a qualquer tempo do período letivo (MANAUS, 2016). O artigo 14 do mesmo documento normatiza que o laudo médico é documento obrigatório para efeito de registro escolar, entretanto, sua apresentação pode ser realizada como um documento suplementar.

Com exceção aos casos das deficiências visíveis, o responsável do estudante deve apresentar um dos seguintes documentos comprobatórios da deficiência: (a) laudo médico; (b) avaliação multiprofissional; ou (c) relatório do professor de AEE (MANAUS, 2016).

Nesse cenário, por mais que a resolução defina que o laudo médico é documento suplementar, não deixa de apresentá-lo na legislação como item obrigatório. Tal disposição vai na contramão do que normatizou a Nota Técnica $n^{\circ}$ 04/2014/MEC/SECADI/DPEE, que orientou quanto aos documentos comprobatórios para a matrícula e cadastro dos estudantes PAEE no Censo Escolar.

Segundo a Nota Técnica, não se pode "[...] considerar imprescindível a apresentação de laudo médico (diagnóstico clínico) por parte do aluno [...] uma vez que o AEE caracteriza-se por atendimento pedagógico e não clínico”. (BRASIL, 2014, p.3).

Em contrapartida o Plano de AEE, elaborado pelo professor especializado, pode ser utilizado como documento comprobatório da matrícula e potencializar o atendimento do estudante na escola. Nesse cenário, "[...] o direito das pessoas com deficiência à educação não poderá ser cerceado pela exigência de laudo médico" (BRASIL, 2014, p. 4).

O laudo médico traz grandes implicação para a elegibilidade dos estudantes que usufruem dos serviços de Educação Especial. Uma dessas implicações diz respeito ao ingresso do estudante a esses serviços sem apresentação do laudo. Prieto e Sousa (2007) visualizaram aspectos 
relacionados, ao identificarem como se implementou em São Paulo, o atendimento de estudantes com deficiência mental, no período de 1997 a 2001. As pesquisadoras apontaram que apesar do fato de 107 estudantes serem classificados como deficientes mentais, apenas 67 possuíam laudo psicológico e apenas 4 laudo médico.

Considerando então que no ano de 2017 foi declarada a matrícula de 2.316 estudantes com deficiência no município de Manaus (MANAUS, 2017; VINENTE, 2017), cabe aqui questionar: (a) quais os critérios utilizados para avaliação desses estudantes? (b) que instrumentos foram utilizados? (c) os familiares desses estudantes foram ouvidos? (d) há na secretaria convênios para a identificação desses alunos? (e) a equipe que realiza essa avaliação tem condições de trabalho adequadas?

Pletsch (2012), Nozu (2013), Semkiv (2014) e Pietrobom (2016) também contextualizam as dificuldades referentes ao processo de identificação, encaminhamento e avaliação dos estudantes PAEE, bem como a necessidade de um suporte adequado tanto referente à formação de equipes interdisciplinares quanto ao apoio pedagógico prestado aos professores e gestores das redes de ensino.

Ao citarmos o grande quantitativo de estudantes em Manaus classificados no grupo de estudantes com deficiência intelectual, observamos outra questão a ser discutida, tal como o processo de identificação de estudantes com altas habilidades/superdotação. No ano de 2017, foi informada a matrícula de apenas 5 estudantes nessa categoria (MANAUS, 2017; VINENTE, 2017).

Assim sendo, é preciso considerar que Manaus é a sétima capital mais populosa do país, o que nos leva a inferir que esse quantitativo de crianças com altas habilidades/superdotação deveria ser bem superior. No entanto, esse grupo provavelmente não foi identificado da forma como se espera. Dessa maneira, os critérios de identificação, encaminhamento e avaliação dos estudantes com altas habilidades/superdotação também apresenta 
limitações, como visualizado nos estudos de Souza (2011), Ragni (2012) e Marques (2013).

Com diferentes disposições legais na legislação municipal fica evidente a permanência da caracterização desses estudantes em determinados grupos, trazendo à discussão a questão do estigma, do preconceito e da discriminação (PLETSCH, 2012; NOZU, 2013; CORRÊA, 2013; SEMKIV, 2014, BATISTA, 2015). Ainda assim, a perspectiva de que a não obrigatoriedade do laudo médico permite potencializar o aspecto pedagógico da AEE, contribui para o rompimento do modelo médico/clínico que permeou a Educação Especial nos últimos anos.

\section{Conclusão}

O presente estudo teve como objetivo analisar os critérios de encaminhamento dos estudantes com deficiência aos serviços de Educação Especial em Manaus.

Foi possível verificar que, embora os primeiros registros de atendimento aos estudantes com deficiência intelectual e auditiva tenham sido de 1892, apenas em 1943 se deram as primeiras iniciativas em âmbito privado para o atendimento desses estudantes, com a instalação do Instituto Montessoriano.

No âmbito da Secretaria Municipal de Educação apenas em 1991 houve a institucionalização da Educação Especial por meio da publicação da Lei $\mathrm{n}^{\circ}$ 050/1991. Com a matrícula dos estudantes a partir de 1991, foi observada então a primeira iniciativa municipal para identificação, avaliação e encaminhamento desses estudantes aos serviços de Educação Especial, por meio da criação do Núcleo/Seção de Educação Especial.

Com a reorganização da Seção de Educação Especial e a criação do SADEM pode-se visualizar com base nos dados, a avaliação psicológica e a emissão de laudos médicos e pareceres técnicos, no sentido de encaminhamento dos estudantes aos serviços especializados. Com a 
implantação do Centro Municipal de Educação Especial (2003) e do Complexo Municipal de Educação Especial (2007) observou-se que os critérios de identificação permaneceram os mesmos, bem como os critérios de encaminhamento aos serviços de Educação Especial do município.

Ainda assim, os critérios até hoje não estão bem delineados na legislação municipal, nem claros para os participantes do estudo. Dessa forma, vislumbramos um campo fértil para pesquisa, no sentido de constituição do histórico de oferta dos serviços e obtenção de dados mais consistentes sobre o processo de identificação, avaliação e encaminhamento desses estudantes.

Na literatura científica da área de Educação Especial encontramos poucos estudos no âmbito do município que forneçam dados mais precisos sobre como eram e são realizadas as avaliações. Mais estudos são necessários para identificar o quantitativo de sessões, as principais queixas, o histórico de fracasso escolar, a questão do registro e acompanhamento, bem como a participação da família nesse processo.

No contexto atual, com a avaliação, a identificação e $\quad$ o encaminhamento sendo realizados por meio do CMEE, a presente pesquisa suscitou reflexões sobre as condições de trabalho da equipe multiprofissional responsável pela emissão dos laudos e dos pareceres técnicos, bem como os critérios utilizados nas avaliação. Dessa forma, é necessário questionar o motivo da identificação de tantos estudantes com deficiência intelectual matriculados no sistema de ensino e o baixíssimo quantitativo de estudantes com altas habilidades/superdotação encaminhados aos serviços especializados.

\section{Referências}

BATISTA, C. P. Política pública de inclusão: atendimento de educandos com deficiência visual no município de Manaus/AM. 2015. 123f. Dissertação (Mestrado em Educação) - Universidade Federal do Amazonas, Manaus, 2015. 
BRASIL. Decreto $n^{0} 7.611$, de 17 de novembro de 2011: dispõe sobre a educação especial, o atendimento educacional especializado e dá outras providências. Diário Oficial [da] República Federativa do Brasil, Brasília, DF, 17 nov. 2011.

Lei $\mathrm{n}^{0}$ 12.796, de 4 de abril de 2013: altera a Lei $\mathrm{n}^{0}$ 9.394, de 20 de dezembro de 1996, que estabelece as diretrizes e bases da educação nacional, para dispor sobre a formação dos profissionais da educação e dar outras providências. Diário Oficial [da] República Federativa do Brasil, Brasília, DF, 04 abr. 2013.

Lei $\mathrm{n}^{\circ}$ 9.394, de 20 de dezembro de 1996: estabelece as diretrizes e bases da educação nacional. Diário Oficial [da] República Federativa do Brasil, Brasília, DF, 20 dez. 1996.

Nota Técnica $n^{o}$ 04/2014 MEC/SECADI/DPEE: Orientação quanto a documentos comprobatórios do cadastro de alunos com deficiência, transtornos globais do desenvolvimento e altas habilidades/superdotação no Censo Escolar. Brasília, DF, 23, jan. 2014.

Política Nacional de Educação Especial na Perspectiva da Educação Inclusiva. Diário Oficial [da] República Federativa do Brasil, Brasília, DF, jan. 2008 .

. Resolução CNE/CEB n 2, de 11 de setembro de 2001: institui as Diretrizes Nacionais para a Educação Especial na Educação Básica. Diário Oficial [da] República Federativa do Brasil. Brasília, DF, 14 set. 2001.

CORRÊAA, T. C. Avaliação, diagnóstico e encaminhamento de crianças com necessidades educacionais especiais no sistema municipal de ensino de LondrinaPR. 2013. 126f. Dissertação (Mestrado em Educação) - Universidade Estadual de Londrina, Londrina, 2013.

FLICK, U. Introdução à pesquisa qualitativa. 3. ed. Tradução de Joice Elias Costa. Porto Alegre: Artmed, 2009.

GARCIA, R. M. C. Políticas para a educação especial e as formas organizativas do trabalho pedagógico. Revista Brasileira de Educação Especial. Marília, v. 12, n. 3, p. 299-316, set/dez, 2006.

GIL, A. C. Métodos e técnicas de pesquisa social. 5. ed. São Paulo: Atlas, 2002.

. Como elaborar projetos de pesquisa. 4. ed. São Paulo: Atlas, 2008.

HARLOS, F. E.; DENARI, F. E.; ORLANDO, R. M. Análise da estrutura organizacional e conceitual da Educação Especial brasileira (2008-2013). Revista Brasileira de Educação Especial, Marília, v. 20, n. 4, p. 497-512, out./dez., 2014.

IBGE. Instituto Brasileiro de Geografia e Estatística. IBGE Cidades. Disponível em: <https://cidades.ibge.gov.br/brasil/am/manaus/panorama>. Acesso em: mai. 2018.

JANNUZZI, G. M. A educação do deficiente no Brasil: dos primórdios ao início do século XXI. Campinas: Autores Associados, 2004. 
MANAUS. Lei n 050, de 4 de janeiro de 1991: dispõe sobre a implantação da Educação Especial na Rede Municipal de Ensino. Diário Oficial do Município de Manaus. Manaus, AM, 4 jan. 1991.

Lei $\mathrm{n}^{\circ}$ 1.102, de 09 de março de 2007: cria o Complexo Municipal de Educação Especial André Vidal de Araújo e dá outras providências. Diário Oficial do Município de Manaus $n^{\circ}$ 1679. Manaus, AM, 08 mar. 2007.

. Lei $\mathrm{n}^{\circ} 452$, de 26 de novembro de 1998: cria na estrutura administrativa da Secretaria Municipal de Educação, as escolas municipais que especifica e dá outras providências. Diário Oficial do Município de Manaus. Manaus, AM, 26 nov. 1998.

Manual da Educação Especial da Secretaria Municipal de Educação. s.d.

Parecer $n^{\circ}$ 2015/03812: Secretaria Municipal de Educação: Subsecretaria de Gestão Educacional: Departamento de Gestão Educacional: Gerência de Educação Especial. Processo 2017/03812. Folha 50. Manaus, AM, 2017.

. Resolução $\mathrm{n}^{\circ}$ 010/CME, de 28 de julho de 2011: institui os procedimentos e orientações para Educação Especial na Perspectiva da Educação Inclusiva no Sistema Municipal de Ensino de Manaus. Diário Oficial do Município de Manaus. Manaus, AM, 20 jul. 2011.

Resolução $\mathrm{n}^{\circ}$ 005/CME, de 18 de dezembro de 2003: dispõe sobre procedimentos e orientações a serem observados para oferta da Educação Especial no Sistema Municipal de Ensino a partir de 2003. Diário Oficial de Manaus. Manaus, AM, 18 dez. 2003.

Resolução $\mathrm{n}^{0}$ 011/CME/2016, de 02 de junho de 2016: Institui novos procedimentos e orientações para Educação Especial, na perspectiva da Educação Inclusiva, no Sistema Municipal de Ensino de Manaus. Diário Oficial do Municipio de Manaus. Manaus, AM, 02 jun. 2016.

Serviço de Avaliação Diagnóstica da Educação Especial do Município SADEM: integração: abrace essa causa. Manaus: Departamento de Ensino Divisão de Ensino - Seção de Educação Especial, 1997 (Folder Informativo).

MANZINI, E. J. Entrevista semi-estruturada: análise de objetivos e de roteiros. In: SEMINÁRIO INTERNACIONAL SOBRE PESQUISA E ESTUDOS QUALITATIVOS. 2004. Bauru. A pesquisa qualitativa em debate. Anais...Bauru: USC, 2004.

MARQUES, D. M. C. Reconhecimento por meio de indicadores da precocidade do aluno na educação infantil. 2013. 158f. Dissertação (Mestrado em Educação Especial) - Universidade Federal de São Carlos, São Carlos, 2013.

MARQUES, M. P. S. D. O Acesso de Pessoas com Deficiência ao Sistema Público de Ensino de Manaus na Percepção dos Professores. 2010. 149f. Tese (Doutorado em Ciências: área Psicologia) - Faculdade de Filosofia, Ciências e Letras de Ribeirão Preto, Universidade de São Paulo, Ribeirão Preto, 2010.

MATOS, M. A. S. Cidadania, diversidade e educação inclusiva: um diálogo entre a teoria e a prática na rede municipal de Manaus. 2008. 229f. Tese (Doutorado em Educação) - Universidade Federal do Rio Grande do Sul, Porto Alegre, 2008. 
MENDES, E. G. A radicalização do debate sobre inclusão escolar no Brasil. Revista Brasileira de Educação. Rio de Janeiro, v. 11, n. 33, p. 387-405, set./dez., 2006.

MENDES, E. G.; CIA, F. ONEESP: um Observatório Nacional para a comunidade da Educação Especial. In: MENDES, E. G.; ALMEIDA, M. A. (Org.). A pesquisa sobre inclusão escolar em suas múltiplas dimensões: teoria, política e formação. Marília: ABPEE, 2012.

MILANESI, J. B. Organização e funcionamento das salas de recursos multifuncionais em um município paulista. 2012. 183 f. Dissertação (Mestrado em Educação Especial) - Universidade Federal de São Carlos, São Carlos, 2012.

NASCIMENTO, A. C. A.; OLIVEIRA, K. B.; MARINHO, M. F. B. Educação Inclusiva no Contexto Amazônico: formação de professores. Manaus: EDUA, 2007.

NOZU, W. C. S. Política e gestão do atendimento educacional especializado nas salas de recursos multifuncionais de Paranaíba/MS: uma análise das práticas discursivas e não discursivas. 2013. 241f. Dissertação (Mestrado em Educação) Universidade Federal da Grande Dourados, Dourados, 2013.

OLIVEIRA, L. M. N. Trabalho pedagógico na Educação Especial: o professor de sala de recursos e sua implicação na escolarização dos alunos com baixa visão. 2016. 142f. Dissertação (Mestrado em Educação) - Universidade Federal de São Carlos, Sorocaba, 2016.

PIETROBOM, F. O. Avaliação e encaminhamento de crianças com deficiência para o Atendimento Educacional Especializado na rede municipal de Dourados/MS. 2016. 94f. Dissertação (Mestrado em Educação) - Universidade Federal da Grande Dourados, Dourados, 2016.

PLETSCH, M. D. Educação Especial e Inclusão Escolar: uma radiografia do atendimento educacional especializado nas redes de ensino da Baixada Fluminense/RJ, Ciências Humanas e Sociais em Revista, RJ, EDUR, V. 34, n.12, jan / jun, p. 31-48, 2012.

PRIETO, R. G. SOUSA, S. Z. L. Educação Especial: atendimentos em salas de recursos na rede municipal de São Paulo. Educação. Santa Maria, v. 32, n. 2, p. 375-396, 2007.

RAGNI, R. A. Reconhecimento do talento em alunos com perdas auditivas do ensino básico. Tese (Doutorado em Educação Especial) - Universidade Federal de São Carlos, São Carlos, 2012.

SANTOS, L. M. A política pública de educação do município de Manaus: o atendimento educacional especializado na organização escolar. 2011. 209f. Dissertação (Mestrado em Educação) - Universidade Federal do Amazonas, Manaus, 2011.

SANTOS, L. M. T. As percepções dos usuários e usuárias da classe especial sobre esse serviço educacional. 102f. Dissertação (Mestrado em Educação) - Universidade do Amazonas, Manaus, 1998.

SEMKIV, S. I. A. L. Análise da dinâmica de avaliação e encaminhamento de crianças com necessidades educacionais especiais num sistema municipal de ensino. 
2014. 172f. Dissertação (Mestrado em Educação) - Universidade Estadual do Centro-Oeste, 2014.Guarapuava-PR, 2014.

SILVA, M. F. N. Encaminhamento de alunos para salas de recursos: análise sobre os argumentos apresentados por professores de classes comuns. 2010. 146f. Dissertação (Mestrado em Educação) - Faculdade de Educação, Universidade de São Paulo, São Paulo, 2010.

SOUZA, P. M. Identificação e caracterização dos alunos com deficiência, transtornos globais do desenvolvimento e altas habilidades/superdotação, matriculados nas classes comuns do ensino regular, na rede pública estadual, em município do interior paulista. Dissertação (Mestrado em Ciências) - Faculdade de Filosofia, Ciências e Letras de Ribeirão Preto, Universidade de São Paulo, Ribeirão Preto, 2011.

VINENTE, S. Política e organização pedagógica do serviço de atendimento educacional especializado em Manaus. 2017. 176f. Dissertação (Mestrado em Educação Especial) - Universidade Federal de São Carlos, São Carlos,2017.

Recebido em junho de 2019.

Aprovado em janeiro de 2020. 